\title{
Original Biliary sphincteroplasty facilitates retrieval of Alticle proximally migrated plastic biliary stent
}

\author{
Dharmesh K Shah, Samit S Jain, Piyush O Somani, Pravin M Rathi
}

ABSTRACT

Department of Gastroenterology, Topiwala National Medical College (TNMC) and

BYL Nair Hospital,

Mumbai - 400008, India

Correspondence:

Dr. Pravin M Rathi

Email: rathipmpp@gmail.com
Background and aim: Proximal migration of biliary stents presents a technical challenge for the therapeutic endoscopist. It may require multiple, complicated corrective procedures resulting in significant morbidity to the patients. In this study we evaluated the utility of balloon biliary sphincteroplasty with CRE ${ }^{\mathrm{TM}}$ (Controlled Radial Expansion) Balloon Dilator on retrieval of proximally migrated biliary stents.

Methods: We identified patients from our ERCP database who presented with proximal migration of biliary stent, between August 2011 and October 2013. Patients in whom the stent could not be retrieved with conventional methods, balloon sphincteroplasty was performed with a 12 mm CRE ${ }^{\mathrm{TM}}$ Balloon Dilator (Boston Scientific). Stent removal was attempted with extraction balloon or basket thereafter.

Results: We identified 28 patients with proximal migration of biliary stents, placed for benign diseases of the common bile duct. Stent removal was successful in 18 patients (64.28\%) with help of an extraction balloon or basket. Of the remaining 10 patients, balloon sphincteroplasty was successfully followed by stent removal in eight patients.

Conclusions: Balloon biliary sphincteroplasty increases the success rate of retrieving proximally migrated biliary stents. The procedure is safe, technically easy and yields a good success rate in our experience.

KEYWORDS: Balloon biliary sphincteroplasty, biliary stent, stent migration

\section{Introduction}

Endoscopic biliary stenting is used to treat a wide variety of biliary and pancreatic disorders. Stent migration is a rare but important complication. Published reports indicate that proximal or distal displacement may occur in up to $10 \%$ of patients with malignant strictures. The incidence may be higher in benign disease. ${ }^{1,2}$ Shorter and single stents have been shown to have a higher rate of migration. ${ }^{3}$ Proximal migration of a biliary stent can compromise bile drainage, mimicking stent occlusion. ${ }^{4}$ It presents a technical challenge that causes significant morbidity to the patient, as it may require multiple, complicated corrective procedures. Various methods have been described for retrieval of a proximally migrated stent. These techniques are classified into three categories: 1) indirect traction with a stone extraction balloon catheter, 2) direct traction on the stent with various 
accessories like snare and rat tooth forceps and 3) retrieval after cannulating the stent lumen with the help of a Soehendra screw extractor.

We reviewed the successful endoscopic retrieval methods for proximally migrated biliary stents. Balloon sphincteroplasty with CRETM Balloon Dilator was tried in patients where conventional methods failed to retrieve the stent. Removal of the stent was attempted with an extraction balloon or basket after sphincteroplasty.

\section{Methods}

Patients who presented with proximal migration of biliary stent were identified from our ERCP database between August 2011 and October 2013. Proximal migration was confirmed when the distal end of the stent was endoscopically invisible at the papillary orifice and the stent was seen in the biliary tree on fluoroscopy. Successful stent retrieval was defined when the distal end of the stent was brought out of the papillary orifice and was removed from the bile duct.

The technical approach used depended on the position of the stent's distal tip. If the tip was near the papilla, we removed stent by dragging the stent downward with an extraction balloon placed above or high alongside the stent, using a guide wire. If the end of the stent was free, we tried to entrap the stent with a basket or polypectomy snare. We initially tried conventional methods in all patients, like extraction with a balloon, basket or polypectomy snare. Most patients had sphincterotomy done during the placement of the stent. We extended the sphincterotomy to facilitate stent removal.

Patients in whom stent retrieval by conventional methods failed, were subjected to balloon sphincteroplasty with a CRE ${ }^{\mathrm{TM}}$ Balloon Dilator (Boston Scientific). The common bile duct was cannulated with a sphincterotome and a 0.035 inch guide wire was placed under fluoroscopic guidance into the right or left duct. We passed 10-11-12 mm sized CRE balloon over the guide wire and inflated up to $12 \mathrm{~mm}$ with water, using an inflation pressure of 8 ATM for one minute (Figure 1). Stent extraction was attempted again after balloon sphincteroplasty.

\section{Results}

During the study period 750 ERCPs were performed for benign biliary disease. Twenty-eight patients suffered proximal migration of their biliary stent. The incidence of stent migration in our study was $3.73 \%$ but this may not reflect the exact incidence of biliary stent migration because some of the patients were referred to us from other centers.

Technical success rate of stent removal with conventional methods was $64.28 \%$ (18/28 patients). Ten patients in whom the biliary stent could not be retrieved, biliary sphincteroplasty with a CRE ${ }^{\mathrm{TM}}$ Balloon Dilator was performed and was followed by another attempt at stent removal. Profile of these patients and results are shown in Tables $\mathbf{1}$ and 2. In patients with difficult to retrieve proximally migrated biliary stent, the median duration of stenting was 12.2 weeks (range: 7 - 60). In six patients, stent migration was diagnosed at the time of routine stent removal. Rest of the patients were diagnosed at other centers and referred to our hospital for stent retrieval.

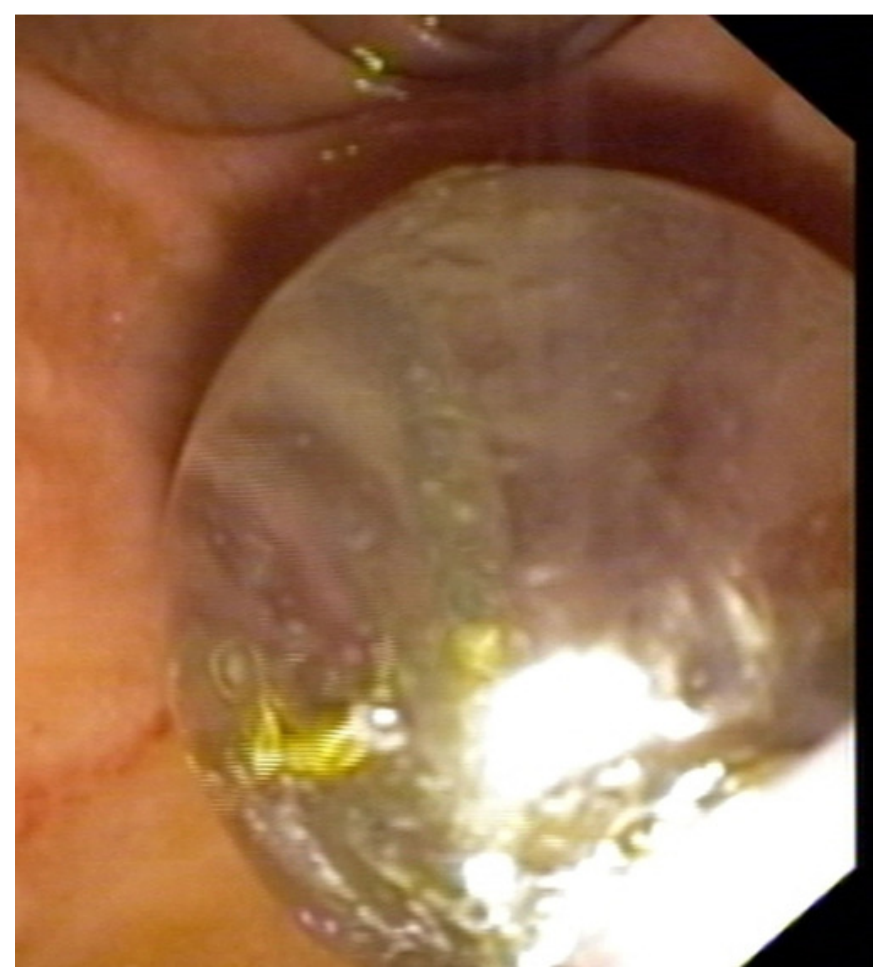

Figure 1 Balloon sphincteroplasty being done in a patient with difficult to remove plastic biliary stent

Table 1: Results of endoscopic retrieval of proximally migrated biliary stents

\begin{tabular}{ll}
\hline Parameter & $\begin{array}{c}\text { No. of patients } \\
(\%)\end{array}$ \\
\hline Total patients & 28 \\
Successful retrieval & $18(64.28 \%)$ \\
Retrieval technique & \\
Extraction balloon & $8(28.57 \%)$ \\
Dormia basket & $4(14.28 \%)$ \\
Balloon and Dormia basket & $4(14.28 \%)$ \\
Rat tooth forceps & $2(7.14 \%)$ \\
Stent not retrieved by conventional method & $10(35.72 \%)$ \\
Success rate of stent removal after balloon & \\
sphincteroplasty & $8 / 10(80 \%)$ \\
Overall success rate & $26 / 28(92.85 \%)$ \\
\hline
\end{tabular}


Table 2: Profile of patients with difficult to remove, proximally migrated biliary stents, who underwent biliary sphincteroplasty

\begin{tabular}{|c|c|c|c|c|c|}
\hline & Age (years)/ Sex & Indication for stent placement & $\begin{array}{l}\text { Size of } \\
\text { stent }\end{array}$ & Presentation & $\begin{array}{l}\text { Success of stent } \\
\text { removal after } \\
\text { sphincteroplasty }\end{array}$ \\
\hline$\overline{\text { Patient } 1}$ & 30/female & Choledocholithiasis & $10 \mathrm{~F}$ & Uncomplicated & Successful \\
\hline Patient 2 & $42 /$ male & Choledocholithiasis & $10 \mathrm{~F}$ & Uncomplicated & Successful \\
\hline Patient 3 & $34 /$ female & Choledocholithiasis & $10 \mathrm{~F}$ & Uncomplicated & Successful \\
\hline Patient 4 & $45 /$ male & Benign distal CBD stricture & $7 \mathrm{~F}$ & Abdominal pain & Successful \\
\hline Patient 5 & $50 /$ female & Choledocholithiasis & $10 \mathrm{~F}$ & Uncomplicated & Successful \\
\hline Patient 6 & $38 /$ female & Choledocholithiasis & $10 \mathrm{~F}$ & Uncomplicated & Successful \\
\hline Patient 7 & $31 /$ female & Benign distal CBD stricture & $7 \mathrm{~F}$ & Uncomplicated & Successful \\
\hline Patient 8 & $41 /$ male & Choledocholithiasis & $7 \mathrm{~F}$ & Uncomplicated & Successful \\
\hline Patient 9 & $28 /$ male & Choledocholithiasis & $10 \mathrm{~F}$ & Uncomplicated & Unsuccessful \\
\hline Patient 10 & $41 /$ female & Benign distal CBD stricture & $10 \mathrm{~F}$ & Abdominal pain & Unsuccessful \\
\hline
\end{tabular}

CBD: common bile duct

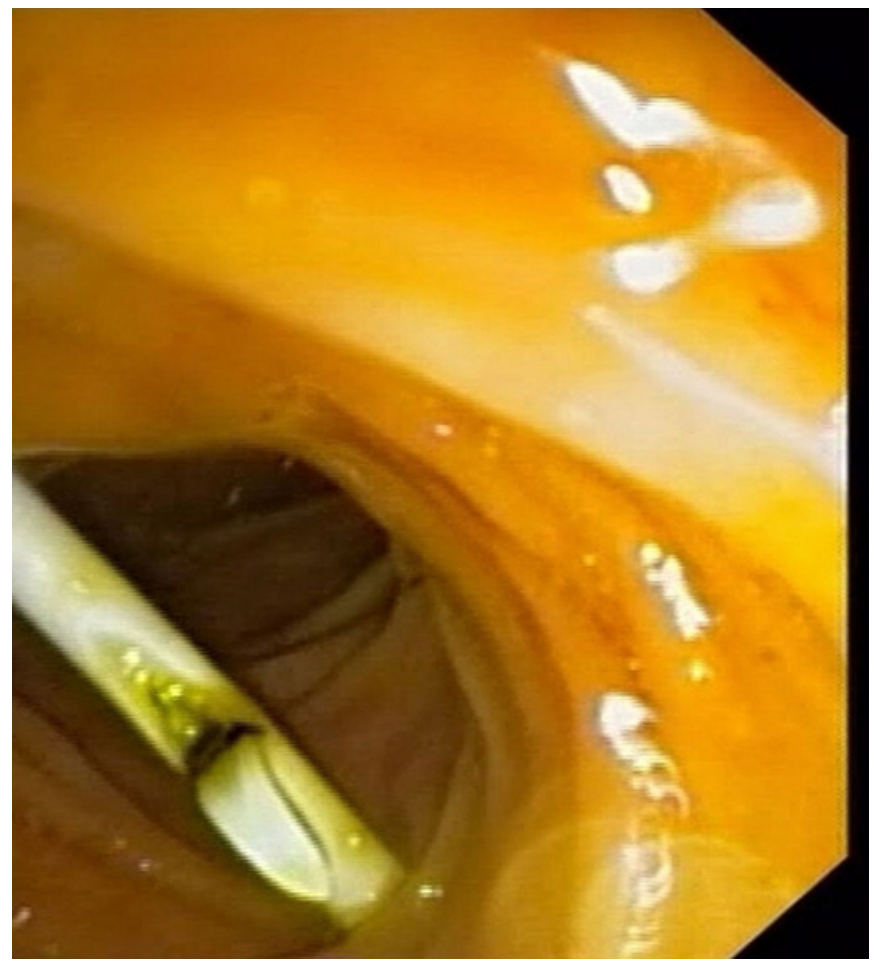

Figure 2 Stent spontaneously slips in to the duodenum with gentle suction after biliary sphincteroplasty

Balloon sphincteroplasty dilated the biliary sphincter and facilitated stent removal. In two patients the stent descended into the duodenum after gentle suction and was then removed using a snare or rat tooth forceps (Figure 2). In rest of the patients, extraction was attempted with a balloon or basket after balloon sphincteroplasty. Stents were successfully retrieved in eight of the 10 patients where conventional techniques had failed. All the patients tolerated the procedure well. There was mild oozing of blood from the papilla in two cases, which was controlled easily with adrenaline spray and balloon tamponade. None of the patients developed postprocedure pancreatitis. We were not able to remove the stent in two patients of which one patient was lost to follow-up and the other had the stent removed surgically.

\section{Discussion}

The success rate of stent removal in our study was $92.85 \%$, which is similar to previous reports from other centers. ${ }^{5-8} \mathrm{The}$ retrieval of a stent that has migrated proximally can be challenging. Only a few reports have described stent recovery techniques and results. Lahoti et al reported that in nearly $46 \%$ patients more than one ERCP was required to retrieve the migrated stent. ${ }^{5}$ It has been suggested that in patients with one failed retrieval attempt, a second stent may be placed with subsequent attempts to remove both stents. If endoscopic retrieval is unsuccessful, surgery is required. ${ }^{6,7}$

If a sphincterotomy has not been done, widening the papillary opening by sphincterotomy facilitates stent removal. Most of our patients underwent biliary sphincterotomy during stent placement. The sphincterotomy was extended to facilitate stent retrieval in all the patients before actually attempting removal of the stent. Compared to sphincterotomy alone, combination of initial sphincterotomy followed by sphincteroplasty is better for opening the papilla and increases the success rate of stent retrieval. Tarnasky et $\mathrm{al}^{2}$ contend that the difficulty in endoscopic retrieval is mainly due to stent migration upstream of a stenotic region, inconsistency between the biliary stent and its axis in patients with no biliary dilatation, and displacement of the bile duct wall by the lower end of the migrated stent. Balloon sphincteroplasty is very useful in such patients because it dilates the stricture and helps in retrieval of the proximally migrated stent. The technique is very simple to perform and does not require any sophisticated instruments or technical expertise. This procedure is routinely done during 
ERCP for removal of large CBD stones. Bleeding and pancreatitis are known complications of balloon sphincteroplasty done for CBD stone extraction. In most of the cases, these are mild and managed conservatively. None of our patients developed pancreatitis. Two patients developed mild oozing that was managed conservatively.

The technical approach employed depends on the position of the stent's distal tip as well as the presence or absence of a prior sphincterotomy. When the tip is near the papilla, it can occasionally be exposed by dragging the stent downward with an extraction balloon placed above or high alongside the stent, using a 0.035 inch guide wire. When the end of the stent is free, especially in a dilated duct, it may be possible to entrap the stent with a basket or polypectomy snare. Once stent is retrieved outside the papilla it can be easily removed with the help of snare or foreign body forceps. The difficulty with baskets and snares, or techniques that require cannulating the stent lumen, is that a free end is required to secure the stent. If the distal stent tip is either impacted against the bile duct wall or oriented proximally, attempts can be made to dislodge the stent distally by balloon traction. Foreign body grasping forceps can be used to grasp the stent shaft anywhere along its length. The main disadvantage of techniques that require cannulating the stent lumen is that proper alignment is necessary to engage the stent and then extract it through the endoscope. A related over-the-wire technique uses a small snare over a guide wire and does not require perfect alignment to secure the stent.

A limitation of our study is the small number of patients enrolled. Secondly, it is a retrospective analysis of our records. We did not compare it prospectively with other methods of migrated stent removal. So a large prospective controlled study is required to validate our findings.

In conclusion, the combination of sphincterotomy with sphincteroplasty is a safe and effective method for retrieving proximally migrated biliary stents that cannot be retrieved by conventional methods. In our experience, the procedure is technically undemanding and offers good success rate.

\section{References}

1. Johanson JF, Schmalz MJ, Geenen JE. Incidence and risk factors for biliary and pancreatic stent migration. Gastrointest Endosc. 1992;38:341-6.

2. Tarnasky PR, Cotton PB, Baillie J, Branch MS, Affronti J, Jowell P, et al. Proximal migration of biliary stents: attempted endoscopic retrieval in forty-one patients. Gastrointest Endosc. 1995;42:513-20

3. Arhan M, Odemis B, Parlak E, Ertugrul I, Basar O. Migration of biliary plastic stents: experience of a tertiary center. Surg Endosc. 2009;23:769-75.

4. Johanson JF, Schmalz MJ, Geenen JE. Incidence and risk factors for biliary and pancreatic stent migration. Gastrointest Endosc. 1992;38:341-6.

5. Lahoti S, Catalano MF, Geenen JE, Schmalz MJ. Endoscopic retrieval of proximally migrated biliary and pancreatic stents: experience of a large referral center. Gastrointest Endosc. 1998;47:486-91.

6. Liebich-Bartholain L, Kleinau U, Elsbernd H, Buchsel R. Biliary pneumonitis after proximal stent migration. Gastrointest Endosc. 2001;54:382-4.

7. Diller R, Senninger N, Kautz G, Tubergen D. Stent migration necessitating surgical intervention. Surg Endosc. 2003; 17:1803-7.

8. Chaurasia OP, Rauws EA, Fockens P, Huibregtse K. Endoscopic techniques for retrieval of proximally migrated biliary stents: the Amsterdam experience. Gastrointest Endosc. 1999;50:780-5. 